\title{
Human Hsp60 could be a possible target of immune response triggered by Hsp60 of Salmonella Enteritidis - a preliminary study
}

\author{
BOŻENA DERA-TOMASZEWSKA ${ }^{1}$, ANNA KRAJEWSKA ${ }^{2}$, RENATA GEOŚNICKA ${ }^{3}$
}

${ }^{1}$ Department of Medical Microbiology, National Salmonella Centre, Medical University of Gdańsk, Gdańsk, Poland

${ }^{2}$ Department of Molecular Microbiology (PhD student), University of Gdańsk, Gdańsk, Poland

3"Immunolab" - Research and Development Company Ltd, Gdynia, Poland

\begin{abstract}
Hsp60 of Salmonella Enteritidis appears to be involved in pathogenesis of infectious processes and host immune responses. Because of the similarities between microbial and human Hsps, a humoral response against microbial Hsps may be destructive for the host due to antigen mimicry leading to an autoimmune response. We have performed a preliminary study to investigate whether the homology between Hsp60 of Salmonella Enteritidis and human Hsp60 really exists. ELISA tests were done with success to show that polyclonal antibodies developed against Hsp60 of Salmonella Enteritidis recognize and cross-react with human Hsp60 and one of its seven synthetic peptides used in the study. It was revealed that the antigenic epitopes, which both the proteins have in common, are located between 409 and 424 amino acid residues of human $H$ sp60 molecule, and are determined by the amino acid sequence of human Hsp60 (409-424) synthetic peptide, the same sequence which was found by other authors to be an immunodominant epitope in patients with acute coronary syndromes. The results show the presence of an immunological and sequence similarity between bacterial Hsp60 and its human counterpart, and suggest that human Hsp60 could be a possible target of immune response triggered by Hsp60 of Salmonella Enteritidis. Salmonella Enteritidis Hsp60 might be potentially involved in autoimmune mechanisms operating in humans. This conclusion must be considered preliminary and hypothesis-generating than hypothesis-proving.
\end{abstract} larity.

Key words: Hsp60, Salmonella Enteritidis, Hsps homology, antigenic mimicry, immunological simi-

(Centr Eur J Immunol 2012; 37 (4): 307-313)

\section{Introduction}

Microbial heat shock proteins (Hsps) appear to be involved in pathogenesis of infectious diseases and host immune responses [1-11]. There is a strong evidence that Hsps of the GroEL class (Hsp60 class) act as immunodominant antigens of many pathogenic microorganisms [5, 12-15]. Despite being conserved, they are also strongly immunogenic and their involvement in autoimmunity has been examined extensively [8, 16-20]. Due to a considerably high degree of sequence homology between bacterial and human heat shock proteins, this protein might be involved in autoimmune disease mechanisms operating in humans [7, 10, 11, 21-30]. Although many studies of Hsps have been conducted with different pathogenic bacteria [2, $6,12,13,31,32]$, including some with Salmonella Choleraesuis, Salmonella Typhimurium and Salmonella Typhi [1, $3,5,33-36]$, there have been only a few studies with Salmonella Enteritidis done [37]. It was revealed that Hsp60 of Salmonella Enteritidis is highly immunogenic. The important role of this protein as a target of the immune response was reported for the laying hens from Salmonella Enteritidis naturally infected flocks - with acute infection (flock I) as well as with occasional bacteria excretion (flock II) [37]. The levels of Hsp60 specific immunoglob- 
ulins in egg yolks, especially during the acute phase of infection were high and related to those against lipopolysaccharide and flagellin, the antigens of the established immunological importance in Salmonella Enteritidis infections. The values obtained from flock II were lower than those for the flock I, being, however, considerably higher than results obtained from the control flock (III). Within Salmonella Enteritidis-negative hens (flock III), the antiHsp60 antibody concentrations were consistently low. To this time still little is known about Hsp60 produced by Salmonella Enteritidis organisms and its possible role in the autoimmune processes. To our knowledge, there has been no published report on the similarity between Hsp60 of Salmonella Enteritidis and human Hsp60. We have thus performed a preliminary study to investigate whether the homology between both these proteins really exists. In this paper we report the identification of one immunogenic 16-mer peptide within human Hsp60 following the screening of a synthetic peptide library with anti-Salmonella Enteritidis Hsp60 serum. Enzyme-linked immunosorbent assays were done successfully to show that polyclonal antibodies developed against Hsp60 of Salmonella Enteritidis recognize and interact with human Hsp60 and one (aa 409-424) of its seven synthetic peptides used in the study. These results show the presence of an immunological and sequence similarity between bacterial Hsp60 and its human homologous protein, and suggest that human Hsp60 could be a possible target of immune response triggered by Hsp60 of Salmonella Enteritidis.

\section{Material and methods}

\section{Salmonella Enteritidis Hsp60 preparation}

The experimental details of the Salmonella Enteritidis Hsp60 preparation were earlier described by DeraTomaszewska et al. [37]. In the purification process, protein which was found to have a molecular weight of approximately $60 \mathrm{kDa}$ under reducing conditions was obtained. Sodium dodecyl sulphate polyacrylamide gel electrophore- sis was used to evaluate the protein concentration and purity. The protein identity was estimated by monoclonal antibodies against Escherichia coli GroEL protein (SPA-870, Stressgen, Victoria, BC, Canada) in the Western immunoblot analysis.

\section{Human Hsp60 fragments synthesis}

A total of seven human Hsp60 fragments were synthesized in the Faculty of Chemistry, University of Gdańsk, Gdańsk, Poland. The experimental details associated with synthesis were described by Wojciechowska et al. [38]. Briefly, knowing the sequence from literature [39] and using the special computer program [40], potential surface oriented regions of human Hsp60 were identified. To define potential antigenic determinants acrophilicity and hydrophilicity profiles of this protein were constructed. Based on the obtained results, seven potential immunogenic human Hsp60 fragments were selected for immunological tests (Table 1). They were of $12,13,14,15$, and 16 amino acids in length. The peptides were synthesized by the solid phase method [41] in a $0.5 \mathrm{mmol}$ scale. The Fmoc/But procedure for synthesis was used. The peptides were homogenous on HPLC and revealed the expected amino acid composition and molecular weight.

\section{Anti-Salmonella Enteritidis Hsp60 polyclonal antibodies induction}

Polyclonal antibodies against Hsp60 of Salmonella Enteritidis were obtained as a result of rabbit hyperimmunization. Before immunization, a blood sample from the marginal vein of the rabbit ear was taken to determine whether the serum contains antibodies against Hsp60. The animal was free from spontaneous antibodies. The rabbit received antigen (20-30 $\mu$ g per injection) subcutaneously four times at intervals of two weeks. The primary injection was given in complete Freund's adjuvant, while all boosts were done in incomplete adjuvant. The rabbit was bled ten days after the last injection. After collection, blood was allowed to clot for $30-60 \mathrm{~min}$ at $37^{\circ} \mathrm{C}$. The clot was then separated from the sides of the collection vessel using a Pas-

Table 1. Synthetic peptides of human Hsp60 protein

\begin{tabular}{ll}
\hline Peptide & Amino acid sequences \\
\hline Hsp60 (25-36) & Ala-Tyr-Ala-Lys-Asp-Val-Lys-Phe-Gly-Ala-Asp-Ala \\
\hline Hsp60 (83-95) & Ser-Ile-Asp-Leu-Lys-Asp-Lys-Tyr-Lys-Asn-Ile-Gly-Ala \\
\hline Hsp60 (119-131) & Leu-Ala-Arg-Ser-Ile-Ala-Lys-Glu-Gly-Phe-Glu-Lys-Ile \\
\hline Hsp60 (238-251) & Glu-Phe-Gln-Asp-Ala-Tyr-Val-Leu-Leu-Ser-Glu-Lys-Lys-Ile \\
\hline Hsp60 (301-314) & Lys-Ala-Pro-Gly-Phe-Gly-Asp-Asn-Arg-Lys-Asn-Gln-Leu-Lys \\
\hline Hsp60 (357-371) & Leu-Leu-Lys-Gly-Lys-Gly-Asp-Lys-Ala-Gln-Ile-Glu-Lys-Arg-Ile \\
\hline Hsp60 (409-424) & Thr-Ser-Asp-Val-Glu-Val-Asn-Glu-Lys-Lys-Asp-Arg-Val-Thr-Asp-Ala \\
\hline
\end{tabular}


teur pipette and placed at $4^{\circ} \mathrm{C}$ overnight. The serum was removed from the clot, and any remaining insoluble material was eliminated by centrifugation $(10,000 \mathrm{~g}, 10 \mathrm{~min}$, $\left.+4^{\circ} \mathrm{C}\right)$. The rabbit anti-Salmonella Enteritidis Hsp60 polyclonal antibodies were tested by Western blotting with an appropriate antigen; additionally, commercially available Escherichia coli GroEL protein (SPP-610, Stressgen, Canada) and bovine serum albumin (BSA, Sigma-Aldrich) were used in the screening. The determination of the antibody titer was performed by ELISA with the respective antigen. The serum was stored at $-20^{\circ} \mathrm{C}$ until used.

\section{Enzyme-linked immunosorbent assay (ELISA) procedure}

Wells on Maxisorp microtiter plates (NUNC, Denmark) received $100 \mu \mathrm{l}$ of $0.05 \mathrm{~mol}$ carbonate-bicarbonate buffer, pH 9.6, containing Salmonella Enteritidis or recombinant human Hsp60 (SPP-740, Stressgen, Canada) antigens at concentrations of $0.1 \mu \mathrm{g} / \mathrm{ml}$ for both, or synthetic peptides at the concentration of $10 \mu \mathrm{g} / \mathrm{ml}$. After an overnight incubation $\left(4^{\circ} \mathrm{C}\right)$, the wells were washed with phosphate buffered

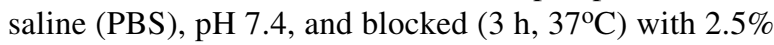
casein (Sigma-Aldrich) solution $\mathrm{pH}$ 7.0. The following steps were carried out using PBS supplemented with Tween 20 $(0.05 \% \mathrm{vol} / \mathrm{vol})$ as a washing buffer. The wells were washed twice, and the rabbit antibodies developed against Salmonella Enteritidis Hsp60 were added at the dilution $1: 1000$ in blocking solution for $16 \mathrm{~h}\left(4^{\circ} \mathrm{C}\right)$, and then washed three times. As a secondary antibody, $100 \mu 1$ of peroxidase-conjugated goat antibodies against rabbit immunoglobulins (DakoCytomatic, Denmark; dilution 1 : 500 in blocking solution) were used. Plates were incubated for $1.5 \mathrm{~h}$ at room temperature and after a next wash step (three times), $200 \mu \mathrm{l}$ of ortho-phenylenediamine (SIGMA FAST, Sigma-Aldrich) per well were added. The reaction was stopped after $30 \mathrm{~min}$ by adding $50 \mu 1$ of sulphuric acid. Absorbance was measured at $492 \mathrm{~nm}$ using an ELISA Reader (microELISA Reader Expert Plus, ASYS Hitach GmbH, Austria). Each test was performed in triplicate. Results were taken from two independent experiments. Wells without rabbit serum were used as blanks (the mean value, calculated for each antigen from measurements of six wells was used as a negative control). The difference between the mean reactivity value of six measurements for each antigen and the proper negative control plus three standard deviations was plotted in the corresponding graphs.

\section{Competition ELISA}

The competition ELISA was performed to confirm the specificity of binding of serum antibodies to human Hsp60. In this assay, one of the ELISA steps described above was modified. The rabbit antiserum against Salmonella Enteritidis Hsp60 was diluted $1: 1000$ in the blocking solution and incubated at $37^{\circ} \mathrm{C}$ for $3 \mathrm{~h}$ with additional $5 \mu \mathrm{g} / \mathrm{ml}$ of
Salmonella Enteritidis Hsp60, or $5 \mu \mathrm{g} / \mathrm{ml}$ of recombinant human Hsp60, or $10 \mu \mathrm{g} / \mathrm{ml}$ of human Hsp60 (aa 409-424) synthetic peptide, and then added to the corresponding wells. The rabbit antiserum absorbed with Hsp60 of Salmonella Enteritidis was tested with three antigens for which the positivity level of absorbance in the ELISA test was indicated, i.e., Salmonella Enteritidis Hsp60, recombinant human Hsp60 and the human Hsp60 (aa 409-424) synthetic peptide. Salmonella Enteritidis Hsp60 was used as a solid phase antigen to examine the antibody-competing effect of recombinant human Hsp60 and synthetic peptide. The assay was continued according to the procedure described above. Each test was performed in triplicate. Two independent experiments were done. The antibody binding to the proper solid phase antigen in the presence and absence of competing Hsps or synthetic peptide was compared.

\section{Results}

The polyclonal antibodies developed against Hsp60 of Salmonella Enteritidis recognized and reacted with Salmonella Enteritidis Hsp60, as well as with the human homologous protein and one of its synthetic fragments. Of these seven synthetic peptides used in the study, only 16 aminoacid fragment located between 409 and 424 amino acid residues of human Hsp60 gave ELISA signals above cutoff value (Fig. 1). Specificity of binding of anti-Salmonella Enteritidis Hsp60 antibodies to human Hsp60 and its 16-mer synthetic peptide (aa 409-424) was confirmed by inhibition of immunoenzymatic reaction by means of absorption of serum antibodies with the excess amount of a given antigen. The reactivity of rabbit antiserum to the human Hsp60 and human Hsp60 (aa 409-424) synthetic peptide was completely lost, and to Salmonella Enteritidis Hsp60 highly reduced (to a very low level), when serum was absorbed with Salmonella Enteritidis Hsp60 protein (Fig. 2). The test revealed also that synthetic fragment

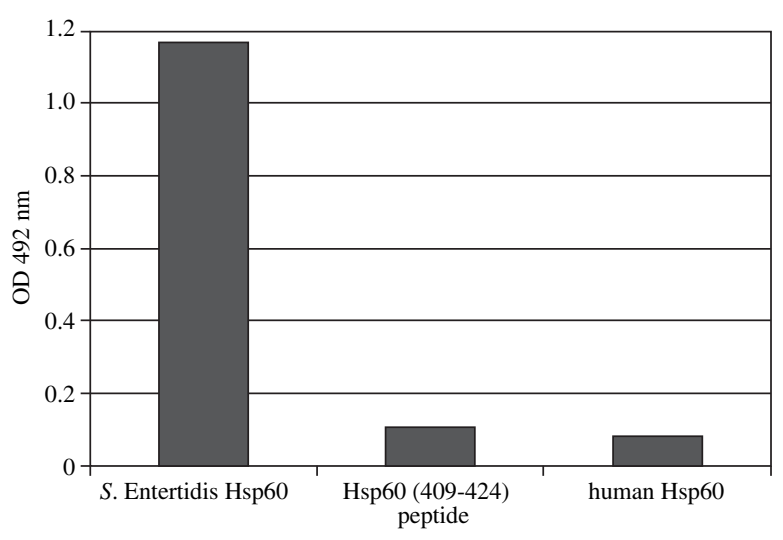

Fig. 1. Reactivity of anti-Salmonella Enteritidis Hsp60 serum to Hsp60 of Salmonella Enteritidis, human Hsp60 (409-424) synthetic peptide and human Hsp60 detected by ELISA 


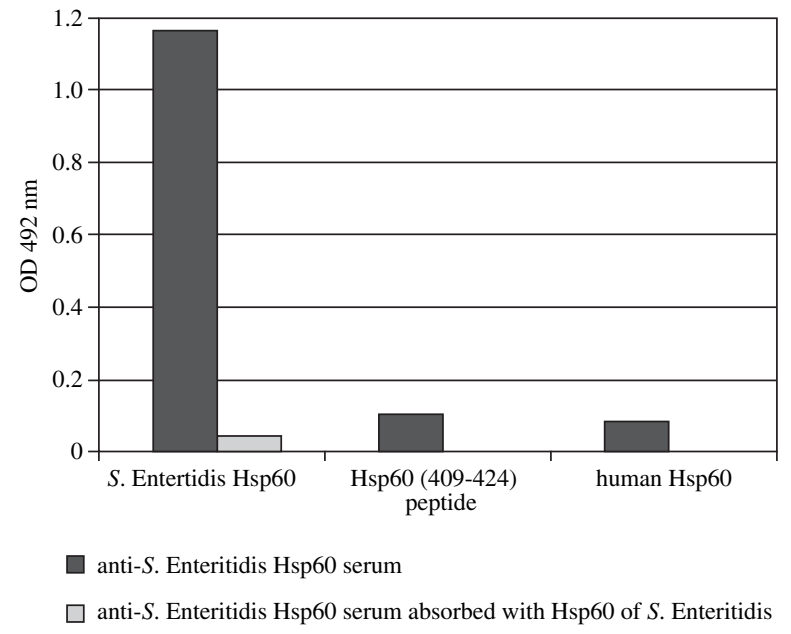

Fig. 2. ELISA results of reactivity of anti-Salmonella Enteritidis Hsp60 serum before and after absorption with homologous Hsp60 to the three following antigens: Salmonella Enteritidis Hsp60, human Hsp60 (409-424) synthetic peptide and human Hsp60

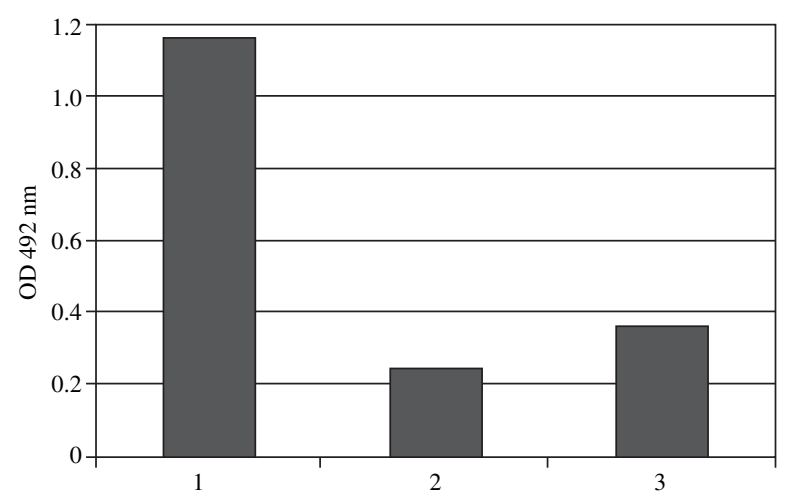

Fig. 3. ELISA results of reactivity of no-absorbed anti-Salmonella Enteritidis Hsp60 serum (1) and serum after absorption with human Hsp60 (409-424) synthetic peptide (2) and human Hsp60 (3) to Hsp60 of Salmonella Enteritidis

(aa 409-424) of human Hsp60 and human recombinant Hsp60 markedly inhibited (over fivefold and over threefold, respectively) the binding activity of rabbit anti-Salmonella Enteritidis Hsp60 antibodies to the solid phase bound Hsp60 of Salmonella Enteritidis (Fig. 3).

\section{Discussion}

On a global scale, Salmonella is responsible for an estimated 3 billion human infections annually. Additionally, data concerning non-typhoidal Salmonella serovars are difficult to obtain, as most patients do not need to consult the health service. The estimates suggest that there are at least three additional cases for every reported case. Most Salmonella enterica serovars cause illness in humans. The epidemiology of human diseases is currently dominated, however, by only a few serovars. Salmonella Enteritidis is the predominant etiologic agent of human salmonellosis in numerous countries worldwide [42]. Salmonella Enteritidis mainly tends to cause a gastroenteritis, which is usually selflimiting, but it is also included to the group of these nontyphoidal Salmonella serovars which may cause human invasive salmonellosis. Salmonellosis has also been associated with long-term and sometimes chronic sequelae. Although the decreasing trend has been currently observed in Salmonella Enteritidis human infections [43, 44], this serovar still remains the "number one" within epidemic Salmonella serovars in many countries and still makes the real health problem. All aspects associated with its pathogenicity, including the possibility of Hsp60 involvement in the human autoimmune response, are worth to be elucidated.

Heat shock proteins constitute a subject of research of many scientists through years. These proteins are induced in prokaryotic as well as eukaryotic species under various conditions of stress [45]. They are traditionally grouped into families of homologous proteins depending of their molecular weight [46]. They are strongly immunogenic and highly conserved, and their involvement in autoimmunity has been examined extensively. Heat shock proteins have been shown to elicit a strong humoral and cellular immune responses during infection by a variety of pathogens. The $60 \mathrm{kDa}$ heat shock proteins family is a focus of interest as a potential antigen in autoimmune diseases. Humoral immune responses to Hsp60 have been found in a number of human autoimmune diseases [7, 47]. Many studies revealed that antibodies against Hsp specifically bind to target tissue of the autoaggressive response. Accumulating evidence from epidemiological or immunopathological studies indicates a role of gastrointestinal tract associated bacteria in the induction and/or perpetuation of autoimmune diseases [7, 27, 28, 48-50]. Anti-self-Hsp60 antibodies could be induced by pathogenic, e.g., Helicobacter pylori [51-53], as well as commensal bacteria like Escherichia coli [47], due to the molecular mimicry. Local inflammatory and immune responses against Helicobacter pylori in the stomach can also induce systemic immune reactions that promote the pathogenesis of extra-gastroduodenal diseases such as atherosclerosis $[46,54]$. The association of antibodies against Hsp60 of Helicobacter pylori production with the development of cardiovascular disease (CDV) was demonstrated by Okada et al. [53]. Furthermore, it was revealed that the 20 amino acid residues $\left(\mathrm{Glu}^{141} \mathrm{Leu}^{160}\right)$ of Helicobacter pylori $\mathrm{Hsp} 60$ might be predominant CVD-associated epitopes that induce anti-human Hsp60 autoantibodies, whose location was predicted in the tertiary structure of human Hsp60. Hirata and colleagues [48] have found that anti-Hsp60 antibodies in patients with rheumatoid arthritis as well as other connective tissue disorders are 
raised by infection with intestinal microorganisms. Antibodies against human Hsp60 cross-reacting with Escherichia coli Hsp60, which significantly exceeded the titers found in normal controls, have been detected in patients with rheumatoid arthritis. These antibodies reacted preferentially with Escherichia coli Hsp60 compared with Mycobacterium tuberculosis Hsp65 or human Hsp60. The antibodies to different enterobacterial Hsp60s are suggested to be associated with the inflammatory process and initiation of ankylosing spondylitis (AS) [27, 50]. It has been demonstrated that patients with AS (HLA-B27 positive) have high titers of antibodies to the $60 \mathrm{kDa}$ heat shock protein of Klebsiella pneumoniae, the Gram-negative bacteria frequently found in the human gut [49]. It has been postulated that Hsp60s of bacteria from the gastrointestinal tract may be involved in the onset of Kawasaki disease (KD) [28], and that an interaction between bacterial and self-Hsp antibody responses could play a role in vascular damage characteristic of KD. Based on Nagata et al. [28] findings, the most likely candidates for bacteria associated with the KD pathogenesis might be Gram-negative microbes, such as Neisseria mucosa or Acinetobacter lwoffii, which have been isolated from KD patients with vascular involvements. The incidence rate of coronary lesions in patients with KD may depend upon how strongly causative agents can induce the initial immune activation and, importantly, how much self-Hsp molecules they can evoke from the cytoplasm or mitochondria to the vascular surface. Interestingly Gramnegative microbes appeared to trigger more self-Hsp than Gram-positive cocci [28]. The intestinal bacteria may represent another example of autoimmune responses triggered by antigenic mimicry of host proteins to microbes. Salmonella Enteritidis should be taken into consideration, especially that in infected patients, the transient intestinal carriage of these Gram-negative, pathogenic bacteria occurs and can last even several months. Some patients may harbour these organisms for up to a year or longer.

The Hsps are antigenic, and the recognition of specific epitopes on such highly conserved antigens may have pathological autoimmune consequences [7]. Because of the similarities between microbial and human Hsps, a humoral response against microbial Hsps may be destructive for the host due to antigen mimicry leading to an autoimmune response. The results of experiments presented in this paper, confirmed that a homology between Hsp60 of Salmonella Enteritidis (Gram-negative, intestinal pathogenic bacteria) and human Hsp60 exists. Enzyme-linked immunosorbent assays were done with success to show that polyclonal antibodies developed against Hsp60 of Salmonella Enteritidis recognize and cross-react with human $\mathrm{Hsp60}$ and one of its seven synthetic peptides used in the study. Their specificity of binding was confirmed by absorption experiments with the proper antigens. It was revealed that the antigenic epitopes which both the proteins have in common are located between 409 and 424 amino acid positions of human Hsp60, and are determined by the amino acid sequence of human Hsp60 (aa 409-424) synthetic peptide: Thr-Ser-Asp-ValGlu-Val-Asn-Glu-Lys-Lys-Asp-Arg-Val-Thr-Asp-Ala. This sequence shows a great overlap with that one presented by Boog and colleagues [55], as containing the cross-reactive epitope between bacterial GroEL and human cognate, which was located by one (LK2) of two monoclonal antibodies generated against human Hsp60. The LK2 antibody reacted with its homologous protein, and additionally showed reactivity with mycobacterial Hsp60 as well as corresponding proteins present in cell extracts of some other bacteria, i.e., GroEL protein of Treponema innocens, Treponema hyodysenteriae, Salmonella Typhimurium, Yersinia enterocolitica and Escherichia coli. The epitope recognized by LK2 antibody is formed by amino acid residues within the sequence 383-419 of the human Hsp60 molecule. Epitopes of bacterial proteins structurally similar to self-antigens present in the host may induce antibodies against self protein structures. It means, that Salmonella Enteritidis Hsp60 potentially might induce autoantibodies. An immune response originally triggered by bacterial antigen might induce an autoimmune reactivity and even mild infections are able to cause cross-reactive response and, as a consequence, the autoimmune disease. The methods used in the performed study and presented in this paper allow to determine explicitly that Hsp60 of Salmonella Enteritidis meets the requirements of molecular mimicry. Due to a sequence homology between Salmonella Enteritidis heat shock protein 60 and its human counterpart, this protein might be potentially involved in autoimmune mechanisms operating in humans. That conclusion must be considered preliminary and hypothesis-generating than hypothesis-proving.

The Hsp60 (409-424) domain, recognized by polyclonal antibodies raised against Salmonella Enteritidis Hsp60, was also recognized by serum antibodies of patients with acute coronary syndromes (ACS) [56]. Sera from groups of patients with unstable angina (UA) and myocardial infarction (MI) reacted against this Hsp60 fragment with significant positive reactivity values relative to the reactivity of other peptides tested. The control group showed a much lower average response to this peptide than the UA and MI groups. Hence, it was concluded by Wysocki and colleagues [56] that peptide Hsp60 (409-424) behaved as an immunodominant epitope in patients with ACS. This suggests that amino acids sequence determined by this peptide might be this antigenic determinant of human Hsp60 which induces production of autoantibodies responsible for development of atherosclerotic lesions.

Serum specimens from the above patients were used for a screening study to determine in ELISA tests if Salmonella Enteritidis Hsp60 specific antibodies are present. All samples from patients with UA and MI showed relatively high levels of anti-Salmonella Enteritidis Hsp60 antibodies (mean value $\mathrm{OD}=0.418$ ) in comparison to the control individuals $(\mathrm{OD}=0.146)$ (data not shown). It is tempting to specu- 
late that Hsp60 of Salmonella Enteritidis, due to the common epitopes with human Hsp60, can potentially generate anti-Hsp60 antibodies that may be responsible for an autoimmune reaction associated, for example, with an accelerated development of atherosclerotic lesions (?). Future studies should clarify whether Hsp60 of Salmonella Enteritidis contributes to the initiation and/or perpetuation of diseases by an autoimmune reaction. The results obtained in this study make a considerable contribution to the research on the heat shock proteins and Salmonella Enteritidis pathogenicity.

\section{The authors declare no conflict of interest.}

\section{References}

1. Ensgraber M, Loos M (1992): A 66-kilodalton heat shock protein of Salmonella typhimurium is responsible for binding of the bacterium to intestinal mucus. Infect Immun 60: 30723078.

2. Kansau I, Labigne A (1996): Heat shock proteins of Helicobacter pylori. Aliment Pharmacol Ther 10 Suppl 1: 51-56.

3. Multhoff G, Hightower LE (1996): Cell surface expression of heat shock proteins and the immune response. Cell Stress Chaperones 1: 167-176.

4. Tang SW, Abubakar S, Devi S, et al. (1997): Induction and characterization of heat shock proteins of Salmonella typhi and their reactivity with sera from patients with typhoid fever. Infect Immun 65: 2983-2986.

5. Panchanathan V, Naidu BR, Devi S, et al. (1998): Immunogenic epitopes of Salmonella typhi GroEL heat shock protein reactive with both monoclonal antibody and patients sera. Immunol Lett 62: 105-109.

6. Garduño RA, Garduño E, Hoffman PS (1998): Surface-associated Hsp60 chaperonin of Legionella pneumophila mediates invasion in HeLa cell model. Infect Immun 66: 4602-4610.

7. Zügel U, Kaufmann SH (1999): Role of heat shock proteins in protection from and pathogenesis of infectious diseases. Clin Microbiol Rev 12: 19-39.

8. Goulhen F, Grenier D, Mayrand D (2003): Oral microbial heatshock proteins and their potential contributions to infections. Crit Rev Oral Biol Med 14: 399-412.

9. Rabczyński M, Adamiec R, Olszewska-Roczniak J (2006): Antibodies anti-HSP 60/65 in atherogenesis, arteriosclerotic plaque risk factor. Adv Clin Exp Med 15: 933-939.

10. Zlacka D, Velek J, Vavrincova P, Hromadnikova I (2007): Antibodies against $M$. bovis $65 \mathrm{KDa}$ heat shock protein and its P180-188 epitope in sera of patients with juvenile idiopathic arthritis. Int J Biomed Sci 3: 185-193.

11. Foteinos G, Xu Q (2009): Immune-mediated mechanisms of endothelial damage in atherosclerosis. Autoimmunity 42: 627-633.

12. Pannekoek Y, van Putten JP, Dankert J (1992): Identification and molecular analysis of a 63-kilodalton stress protein from Neisseria gonorrhoeae. J Bacteriol 174: 6928-6937.

13. Wu YL, Lee LH, Rollins DM, Ching WM (1994): Heat shockand alkaline $\mathrm{pH}$-induced proteins of Campylobacter jejuni: characterization and immunological properties. Infect Immun 62: 4256-4260.
14. Hoffman PS, Garduno RA (1999): Surface-associated heat shock proteins of Legionella pneumophila and Helicobacter pylori: roles in pathogenesis and immunity. Infect Dis Obstet Gynecol 7: 58-63.

15. Lin CS, He PJ, Tsai NM, et al. (2010): A potential role for the Helicobacter pylori heat shock protein 60 in gastric tumorigenesis. Biochem Biophys Res Commun 392: 183-189.

16. López-Hoyos M, Alvarez L, Ruiz Soto M, et al. (2008): Serum levels of antibodies to Chlamydia pneumoniae and human HSP60 in giant cell arteritis patients. Clin Exp Rheumatol 26: 1107-1110.

17. Dieudé M, Gillis MA, Théorêt JF, et al. (2009): Autoantibodies to heat shock protein 60 promote thrombus formation in a murine model of arterial thrombosis. J Thromb Haemost 7: 710-719.

18. Marengo EB, Commodaro AG, Peron JP, et al. (2009): Administration of Mycobacterium leprae rHsp60 aggravates experimental autoimmune uveitis in mice. PLoS One 4: e7912.

19. Skwor T, Kandel RP, Basravi S, et al. (2010): Characterization of humoral immune responses to chlamydial HSP60, CPAF, and CT795 in inflammatory and severe trachoma. Invest Ophthalmol Vis Sci 51: 5128-5136.

20. Belhia F, Gremlich S, Muller-Brochut AC, et al. (2010): Anti$60-\mathrm{kDa}$ hest shock protein antibodies in fetal serum: a biomarker for unexplained small for gestational age fetuses. Gynecol Obstet Invest 70: 299-305.

21. McLean IL, Archer JR, Cawley MI, et al. (1990): Specific antibody response to the mycobacterial $65 \mathrm{kDa}$ stress protein in ancylosing spondylitis and rheumatoid arthritis. Br J Rheumatol 29: 426-429.

22. Yokota S, Tsubaki K, Kuriyama T, et al. (1993): Presence in Kawasaki disease of antibodies to mycobacterial heat shock protein hsp65 and autoantibodies to epitopes of human hsp65 cognate antigen. Clin Immunol Immunopathol 67: 163-170.

23. Rambukkana A, Das PK, Witkamp L, et al. (1993): Antibodies to mycobacterial $65-\mathrm{kDa}$ heat shock protein and other immunodominant antigens in patients with psoriasis. J Invest Dermatol 100: 87-92.

24. Choi JI, Chung SW, Kang HS, et al. (2004): Epitope mapping of Porphyromonas gingivalis hest-shock protein and human hest-shock protein in human atherosclerosis. J Dent Res 83: 936-940.

25. Ayada K, Yokota K, Kobayashi K, et al. (2009): Chronic infections and atherosclerosis. Clin Rev Allergy Immunol 37: 44-48.

26. Nozari Y, Akiash N, Daryani NE, Abdollahi A (2009): Association between Helicobater pylori infection and atherosclerosic coronary artery disease. Iran J Pathol 4: 1-4.

27. Domínguez-López ML, Ortega-Ortega Y, Manríquez-Raya JC, et al. (2009): Antibodies against recombinant heat shock proteins of $60 \mathrm{kDa}$ from enterobacteria in the sera and synovial fluid of HLA-B27 positive ancylosing spondylitis patients. Clin Exp Rheumatol 27: 626-632.

28. Nagata S, Yamashiro Y, Ohtsuka Y, et al. (2009): Heat shock proteins and superantigennic properties of bacteria from the gastrointestinal tract of patients with Kawasaki disease. Immunology 128: 511-520.

29. Matsuura E, Kobayashi K, Matsunami Y, et al. (2009): Autoimmunity, infectious immunity, and atherosclerosis. J Clin Immunol 29: 714-721.

30. Deniz E, Guc U, Buyukbabani N, Gul A (2010): HSP 60 expression in recurrent oral ulcerations of Behçet's disease. Oral Surg Oral Med Oral Pathol Oral Radiol Endod 110: 196-200. 
31. Lin CY, Huang YS, Li CH, et al. (2009): Characterizing the polymeric status of Helicobacter pylori heat shock protein 60. Biochem Biophys Res Commun 388: 283-289.

32. Sinha K, Bhatnagar R (2010): GroEL provides protection against Bacillus anthracis infection in BALB/c mice. Mil Immunol 48: 264-271.

33. Buchmeier NA, Heffron F (1990): Induction of Salmonella stress proteins upon infection of macrophages. Science 248: 730-732.

34. Lindler LE, Hayes JM (1994): Nucleotide sequence of the Salmonella typhi GroEL heat shock gene. Microb Pathog 17: 271-275.

35. Nishimura H, Emoto M, Kimura K, Yoshikai Y (1997): Hsp70 protects macrophages infected with Salmonella choleraesuis against TNF- $\alpha$-induced cell death. Cell Stress Chaperones 2: 50-59.

36. Bansal A, Paliwal PK, Sagi SS, Sairam M (2010): Effect of adjuvants on immune response and protective immunity elicited by recombinant Hsp60 (GroEL) of Salmonella typhi against S. typhi infection. Mol Cell Biochem 337: 213-221.

37. Dera-Tomaszewska B, Wysocki J, Kunikowska D, et al. (2003): Hsp60 specific antibodies in egg yolks from laying hens naturally infected with Salmonella enterica subspecies enterica serovar Enteritidis. Comp Immunol Microbiol Infect Dis 26: $37-45$.

38. Wojciechowska I, Kochańska B, Stelmańska E, et al. (1998): Statherin and its shortened analogues. Pol J Chem 72: 20982102.

39. Venner TJ, Singh B, Gupta RS (1990): Nucleotide sequence and novel structural features of human and Chinese hamster hsp60 (chaperonin) gene families. DNA Cell Biol 9: 545-552.

40. Peptide Companion, version 1.24, CoshiSoft/PeptideSearch 1994.

41. Stewart J, Young J (1984): Solid phase peptide synthesis. In: Pierce Chemical. Co., 2nd ed., Rockford 1984; 71-89.

42. Hendriksen RS, Vieira AR, Karlsmose S, et al. (2011): Global monitoring of Salmonella serovars distribution from the World Health Organization Global Foodborne Infections Network Country Data Bank: results of quality assured laboratories from 2001 to 2007. Foodborne Pathog Dis 8: 887-900.

43. European Food Safety Authority (2010): The Community Summary Report on Trends and Sources of Zoonoses and Zoonotic Agents and Food-borne Outbreaks in the European Union in 2008. EFSA Journal 1496: 23-109.

44. Dera-Tomaszewska B, Kozłowski A (2011): Statystyczna analiza trendu zakażeń Salmonella u ludzi w Polsce w latach 1995-2007. Przegl Epidemiol 65: 351-359.

45. Kaufmann SH (1990): Heat shock proteins and the immune response. Immunol Today 11: 129-136.

46. Knowlton AA (1997): An overview of the heat shock proteins, their regulation, and function. In: Heat shock protein and the cardiovascular system. Knowlton AA (ed.). Kluwer Academic Publishers, Boston 1997; 1-23.

47. Zhu J, Quyyumi AA, Rott D, et al. (2001): Antibodies to human heat-shock protein 60 are associated with the presence and severity of coronary artery disease: evidence for an autoimmune component of atherogenesis. Circulation 103: 10711075.

48. Hirata D, Hirai I, Iwamoto M, et al. (1997): Preferential binding with Escherichia coli hsp60 of antibodies prevalent in sera from patients with rheumatoid arthritis. Clin Immunol Immunopathol 82: 141-148.
49. Cancino-Díaz ME, Pérez-Salazar JE, Domínguez-López L, et al. (1998): Antibody response to Klebsiella pneumoniae $60 \mathrm{kDa}$ protein in familiar and sporadic ancylosing spondylitis: role pf HLA-B27 and characterization as a GroEL-like protein. J Rheumatol 25: 1756-1764.

50. Cancino-Díaz M, Ayala-Narváez H, Burgos-Vargas R, et al. (2000): Recognition of B cells epitopes of the Klebsiella pneumoniae GroEL-like protein by HLA-B27 positive subjects. Microb Pathog 28: 211-220.

51. Birnie DH, Holme ER, McKay IC, et al. (1998): Association between antibodies to heat shock protein 65 and coronary atherosclerosis. Possible mechanism of action of Helicobacter pylori and other bacterial infections in increasing cardiovascular risk. Eur Heart J 19: 387-394.

52. Mayr M, Kiechl S, Willeit J, et al. (2000): Infections, immunity, and atherosclerosis: associations of antibodies to Chlamydia pneumoniae, Helicobacter pylori, and cytomegalovirus with immune reactions to heat-shock protein 60 and carotid or femoral atherosclerosis. Circulation 102: 833-839.

53. Okada T, Ayada K, Usui S, et al. (2007): Antibodies against heat shock protein 60 derived from Helicobacter pylori: diagnostic implications in cardiovascular disease. J Autoimmun 29: 106-115.

54. Sawayama Y, Ariyama I, Hamada M, et al. (2005): Association between chronic Helicobacter pylori infection and acute ischemic stroke: Fukuoka Harasanshin Atherosclerosis Trial (FHAT). Atherosclerosis 178: 303-309.

55. Boog CJ, de Graeff-Meeder ER, Lucassen MA, et al. (1992): Two monoclonal antibodies generated against human hsp60 show reactivity with synovial membranes of patients with juvenile chronic arthritis. J Exp Med 175: 1805-1810.

56. Wysocki J, Karawajczyk B, Górski J, et al. (2002): Human heat shock protein 60 (409-424) fragment is recognized by serum antibodies of patients with acute coronary syndromes. Cardiovasc Pathol 11: 238-243. 